\title{
Differences in the Developmental Patterns of Three Microtubule-associated Proteins in the Rat Cerebellum ${ }^{1}$
}

\author{
ROBERT BERNHARDT, ${ }^{2}$ GERDA HUBER, ${ }^{3}$ AND ANDREW MATUS ${ }^{4}$
}

Friedrich Miescher-Institut, P. O. Box 2543, CH-4002 Basel, Switzerland

\begin{abstract}
The developmental distribution patterns of microtubuleassociated proteins (MAPs) 1, 2, and 3 were studied using three monoclonal antibodies. Immunochemical staining at the light and electron microscopic levels demonstrated the specific localization of each MAP in different cellular and subcellular compartments. (i) MAP2, which is specifically associated with dendritic microtubules in the adult brain, is strictly associated with growing dendrites from the onset of their formation. (ii) MAP3, a recently described MAP of $M_{\mathrm{r}}=$ 180,000 , which in the adult brain is associated with neurofilament-rich axons and glial processes, is associated with axons from the beginning of outgrowth. Although MAP3 is not detectable in granule cells and their parallel fiber axons in the mature cerebellum, it does appear transitorily in these axons during development. (iii) During neuronal differentiation, MAP1 is found first in axons and only later in dendrites where the highest concentrations are eventually to be found. These results indicate that the combined appearance of MAP1 and MAP2 (dendrites) or MAP1 and MAP3 (axons) correlates with the appearance of morphologically distinct microtubules and provide further evidence that specific MAPs are molecular determinants of dendritic and axonal formation.
\end{abstract}

Microtubules contain a set of polypeptides which copolymerize with tubulin during repeated cycles of assembly and disassembly and are therefore known as microtubule-associated proteins (MAPS; Borisy et al., 1975; Slubuda el al., 1976). Brain microtubules possess a particularly rich variety of MAPs, with more than 20 distinct polypeptide bands having been visualized by sodium dodecyl sulfate-polyacrylamide gel electrophoresis (see, for example, Fig. 1 in Huber and Matus, 1984a). The best studied brain MAPS, MAP2 (Borisy et al., 1975; Sloboda et al., 1976; I lerzog and Weber, 1978) and the tau proteins (Witman et al., 1976; Cleveland et al., 1977), are potent promotors of tubulin assembly in vitro. Since the assembly of microtubules is an essential step in the growth of neuronal processes (Seeds et al., 1970; Yamada ef al., 1970; Daniels, 1972),

Received June 4, 1984; Revised September 24, 1984;

Accepted October 3, 1984

' We wish to thank Marcel Ackermann for technical and photographic assistance.

${ }^{2}$ Present address: University of Michigan, Division of Biological Sciences, Ann Arbor, Ml 48109.

${ }^{3}$ Present address: Biotechnology Division, Ciba-Geigy AG, $\mathrm{CH}-4002$ Basel, Switzerland

${ }^{4}$ To whom correspondence should be addressed.
MAPs are potentially important physiologicai regulators of neuronal differentiation.

It has become clear that microtubules of different tissues and cell types are characterized by different MAPs. Thus, a category of high molecular weight MAPs, later identified as MAP2, is exclusively expressed in adult neurons where it is most concentrated in dendrites (Matus et al., 1981, 1983; Caceres et al., 1983, 1984; Wiche et al., 1983; Bernhardt and Matus, 1984; De Camilli el al., 1984). This suggested the possibility that MAP2 could be specifically involved in the formation of dendritic microtubules and hence could play a significant role in the regulation of dendrite growth. This idea found further support from immunohistochemical data of developing brain (Bernhardt and Matus, 1982; Matus et al., 1983; Burgoyne and Cumming, 1984), which showed that MAP2 is present at high concentrations in nascent dendrites. Recent studies with monoclonal antibodies have extended the evidence for cellular and structural specificity of brain MAPs, showing that MAP1 is also concentrated in neuronal dendrites (Bloom et al., 1984; Huber and Matus, 1984a). In addition, we have found that MAPs 1 and 2 and a recently identified new MAP species, MAP3 (Matus et al., 1983; Huber et al., 1985), are also differentially distributed, (i) between various cell types and (ii) within the cytoplasm of the same cell (Matus et al., 1983; Huber and Matus, 1984b)

These differences in the cellular and cytoplasmic distributions of MAPs 1,2 , and 3 have led us to propose a model of neuronal differentiation in which the development of different domains of the nerve cell, such as axon, dendrite, and postsynaptic density, are each established by a specific local cytoskeletal structure (Matus et al., 1983). Local regulators of cytoskeleton formation, such as the MAPs, would then serve to direct this process of neuronal microdifferentiation during the maturation of nerve cells. In the present study we have followed the appearance of MAPs 1, 2, and 3 during cerebellar development. The results demonstrate (i) the transitory appearance of MAPs 1 and 3 in high concentrations at sites where in the adult, they are present at much lower levels and (ii) the specific association of MAP2 with growing dendrites. These data provide further evidence that a complex sequence of molecular events operates during the establishment of the cytoskeletal framework that underlies characteristic cellular morphology

\section{Materials and Methods}

Antibodies. Three monoclonal antibodies directed, respectively, against MAPs 1,2 , and 3 were obtained from mice immunized with the MAP fraction of third-cycle microtubules (Matus et al., 1983: Huber and Matus, 1984a, b) All three antibodies belong to the IgG1 class, and their specificity has previously been established on gel blots of microtubular protein. Anti-MAP1 reacts specifically with the MAP1 parent proteins and also with some proteins of lower molecular weight. Anti-MAP2 recognizes the doublet protein band of MAP2 and some smaller MAP2 fragments. Anti-MAP3, among blotted MAPS, stains a parent protein band of $M_{\mathrm{r}} \simeq 180,000$ and some minor protein bands of lower molecilar weight. On histological sections of adult brain 

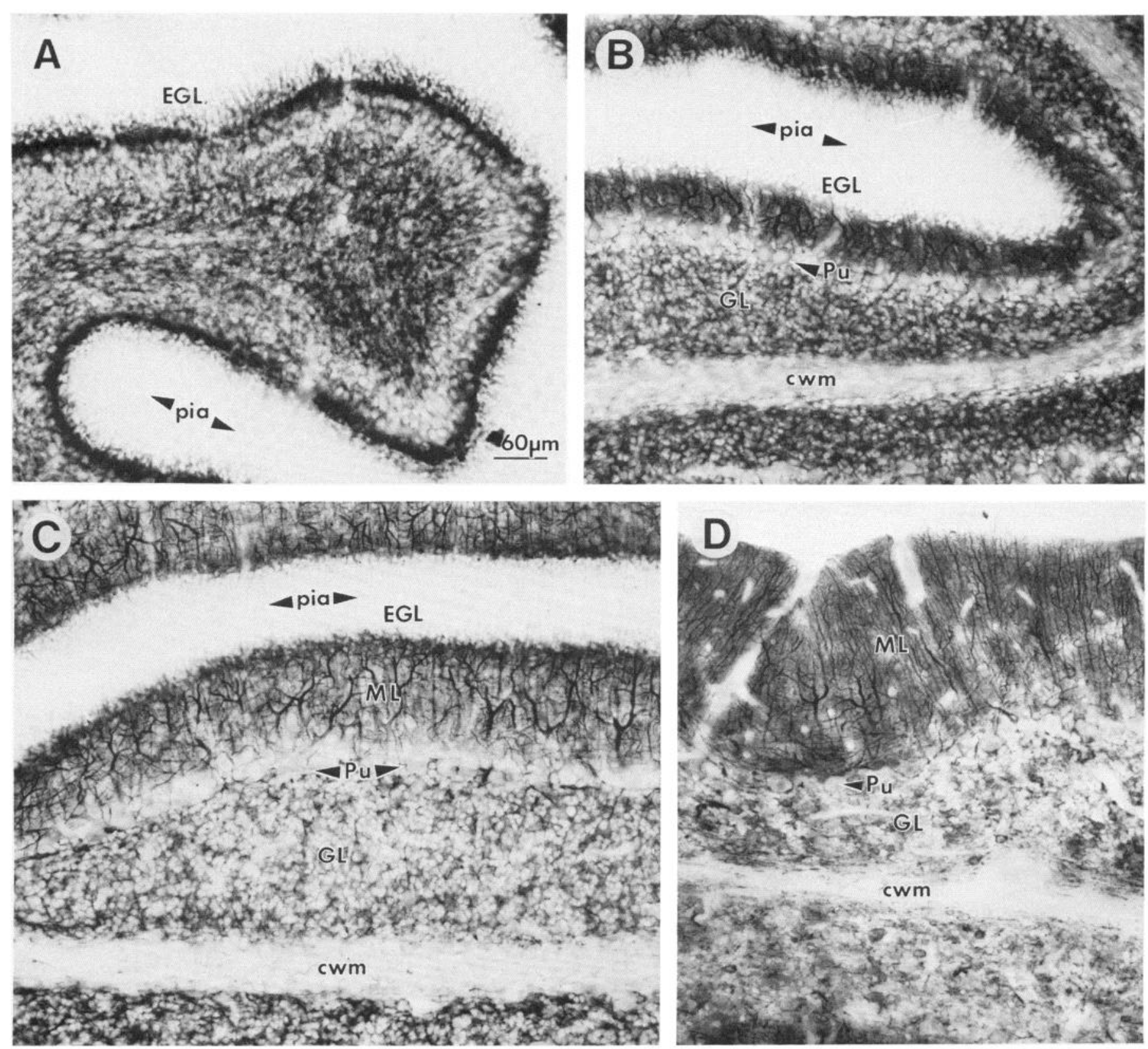

Figure 1. Overview of MAP2 distribution in developing rat cerebellum as revealed in anti-MAP2-stained section from: $A, 3$-day-old; $B, 7$-day-old; $C$, 10day-old, and $D$, adult cerebellum. All micrographs are to the scale indicated in $A$. cwm, central white matter; $E G L$, external granular layer; $G L$, granular layer (internal); $M L$, molecular layer; $P u$, Purkinje cell body layer. The position of the pia between adjacent folia is also indicated.

these three antibodies give distinct staining patterns, which are independent of the method of tissue fixation (Matus et al., 1983; Huber and Matus, 1984a, b). Thus, the three monoclones act as controls for each other, excluding the possibility that fixation or penetration artifacts rather than immunological specificity are responsible for differences in staining patterns.

Immunohistochemistry. Littermate rat pups, aged $3,7,10,14$, and 20 days, and adult animals (older than 70 days) were perfused under Nembutal (Abbott) anesthesia, using 4\% paraformaldehyde and $1 \%$ glutaraldehyde in $0.1 \mathrm{M}$ phosphate buffer. Only brains showing optimal fixation were selected and processed for immunochemical staining. Sections of cerebellar tissue blocks, embedded in $4 \%$ agar, were cut on a Vibratome (Oxford) at a nominal thickness of $50 \mu \mathrm{m}$. Vibratome sections were stored in Tris-buffered saline, supplemented with $0.1 \%$ sodium azide. Cryostat sections of rapidly frozen tissue samples were cut and acetone fixed as previously described (Huber and Matus, 1984b). Within 1 week these cerebellar sections were stained with the antibodies according to the labeled peroxidase technique. For light microscopy, $\alpha$-chloro-1-naphthol was used as a chromogen (Bernhardt and Matus, 1984).
For electron microscopy, the immunoenzymatic reaction was carried out using diaminobenzidine. After postfixation in $1 \% \mathrm{OsO}_{4}$ in $0.1 \mathrm{M}$ cacodylate buffer, sections were dehydrated and embedded in Spurr plastic resin. Ultrathin sections were cut on a Reichert ultramicrotome. Optionally, ultrathin sections were contrasted on the grid with $0.4 \%$ lead citrate in $0.1 \%$ sodium hydroxide.

\section{Results}

\section{MAP2 is dendrite-specific throughout development}

Adult situation. We deal with MAP2 first because its cytological distribution has been the subject of several prior studies and thus forms a standard for comparison with MAPs 1 and 3 . In the adult rat brain MAP2 is present only in neurons, where it is associated with dendritic but not with axonal microtubules (see Bernhardt and Matus, 1984; Carceres et al., 1984; De Camilli et al., 1984). The dendritespecific localization of MAP2 is particularly obvious in the cerebellar 
Purkinje cell. Whereas the dendritic tree is extensively labeled by anti-MAP2 (see Fig. 2C), no immunoreaction product is detectable in axons of the cerebellar white matter (Figs. $1 D$ and 13D).

Developmental pattern. At 3 days postnatal, high concentrations of MAP2 are detected in the Purkinje cell somata (Fig. $2 A$ ) which, because of their close packing appear as a densely stained band below the external granular layer (Fig. $1 A$ ). Strong staining reaction is also associated with the growing Purkinje cell dendrites (Fig. 2A).
By 7 days postnatal and increasingly at 10 days, MAP2 has become concentrated in the distal part of the dendritic tree, from which secondary and tertiary branches are actively growing, (Figs. 1, $B$ and $C$, and $2 B$ ). At the same time, staining in the Purkinje cell body becomes progressively weaker. This gradient of MAP2 reactivity, strong in the distal dendritic tree but decreasing toward the cell body, develops during the second postnatal week (Fig. 2B) and persists in the mature cerebellum (Fig. 2C). Throughout cerebellar
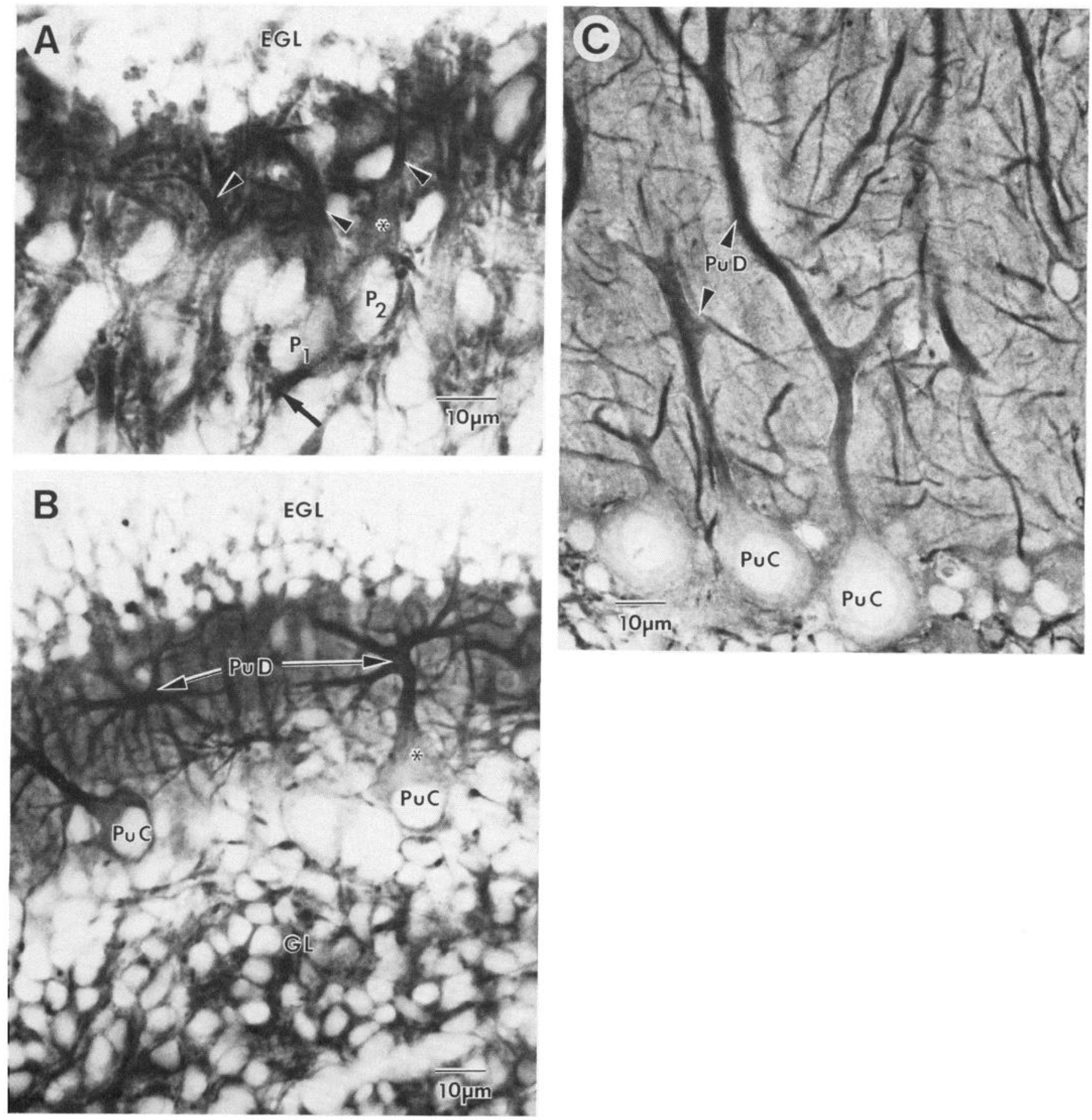

Figure 2. Detail of MAP2 developmental pattern in cerebellar cortex. $A$, In 3-day-old tissue MAP2 is localized in the cytoplasm surrounding Purkinje cell nuclei $\left(P_{1}\right.$ and $\left.P_{2}\right)$. Accumulation of MAP2 occurs in sprouting dendrites (arrowheads). The apical growth cytoplasm $\left(P_{2}\right.$, asterisk) and a Purkinje cell somatic spine $\left(P_{1}\right.$, arrow) also contain high levels of MAP2. $B$, In 10-day-old rat cerebellum, MAP2 is concentrated in the distal part of the Purkinje cell dendritic tree $(P \cup D)$, whereas it is present in the cell body at a lower level (PuC, asterisk). No immunoreaction is detected in the precursor cells of the external granular layer ( $E G L)$, but granule cells arrived in the internal granular layer $(G L)$ are strongly stained by anti-MAP2. $C$, In adult cerebellum, the Purkinje cell dendritic arborization $(P U D)$ is strongly labeled whereas reaction density decreases in the dendritic trunk toward the weakly stained soma (PuC). 
development we do not find any evidence of anti-MAP2-induced staining of axons or glia (see also below). Thus, the dendrite-specific distribution pattern of MAP2 is established at the moment of dendritic outgrowth and is maintained throughout all subsequent stages of dendritic maturation.

\section{MAP1 shows changes in cytoplasmic distribution during neuronal development}

Adult situation. MAP1 is expressed in all neuronal cell types (Fig. $3, A$ and $B$ ), but anti-MAP1 staining intensity varies strikingly between different types of neurons. As previously reported (Huber and Matus, 1984a), it is markedly stronger in Purkinje cells than in granule cells (Figs. $3 A$ and $13 A$ ). In addition, there is in all neurons a pronounced difference of MAP1 concentration between axons and dendrites. Purkinje cell dendrites appear much more intensely stained than the axons of these cells running in the cerebellar white matter (Figs. $3 A$ and $13 A$ ). Whereas weak anti-MAP1 staining occurs in parallel fibers, particularly in the lower regions of the molecular layer, no MAP1 reactivity is detected in the axons of stellate, basket, or Golgi cells (Fig. 3B; see also Huber and Matus, 1984a, b).

Developmental pattern. In the 3-day-old animal, labeling of adjacent cell bodies by anti-MAP1 produces an effectively continuous staining throughout the cerebellar cortex (Figs. $4 A$ and $5 A$ ). MAP1 continues to be expressed by all postmitotic cerebellar neurons during the subsequent stages of development until the mature pattern is reached. In granule cells it is present throughout postmitotic development but is not detected in the dividing precursors of these cells in the external granular layer (Fig. $4, A$ to $D$ ).

Although the neuronal cell types expressing MAP1 do not alter during development, there are characteristic changes in its cytoplasmic distribution. At early stages of development anti-MAP1 strongly stains axons in the central cerebellar tracts which will finally form the white matter. MAP1 reactivity in the central fiber tracts decreases progressively; this happens during the same period that myelination is occurring (Fig. $4, A$ to $D$ ). In the first week after birth, MAP1 is also concentrated in the primordium of the molecular layer and appears to be associated with parallel fiber axons (Figs. 4, $A$ and $B$, and $5 A$ ). The intensity of parallel fiber staining also decreases as cerebellar maturation proceeds. However, axonal staining persists at much reduced levels both in myelinated axons and in a proportion of the more deeply lying parallel fiber axons of the adult cerebellum.

Immunoelectron microscopy of 10-day-old rat cerebellum reveals that only a subset of parallel fiber profiles is stained by anti-MAP1 (Fig. 6). Climbing fibers, however, show no evidence of MAP1 content. Figure $7 D$ illustrates such a climbing fiber, identified by its dense array of microtubules and synaptic vesicles (Palay and ChanPalay, 1974), which shows no immune reaction product, whereas a neighboring Purkinje cell dendrite is clearly stained by anti-MAP1.

Whereas considerable amounts of immunologically detectable MAP1 are already present in axons at 3 days postnatal, distinct MAP1 reactivity in developing Purkinje cell bodies appears only at approximately 7 days, after dendritic outgrowth has already been initiated (cf. Fig. 5, $A$ and $B$ ). In this respect MAP1 differs from MAP2, which accumulates underneath the Purkinje cell membrane prior to dendritic sprouting (Bernhardt and Matus, 1982; Matus et al., 1983). When it does appear, MAP1 is present in the Purkinje cell body, in the growing dendrite, and in the axon, as it emerges from the perikaryon (Fig. 5B). Anti-MAP1 staining, extending through the whole dendritic expansion, remains a striking feature of Purkinje
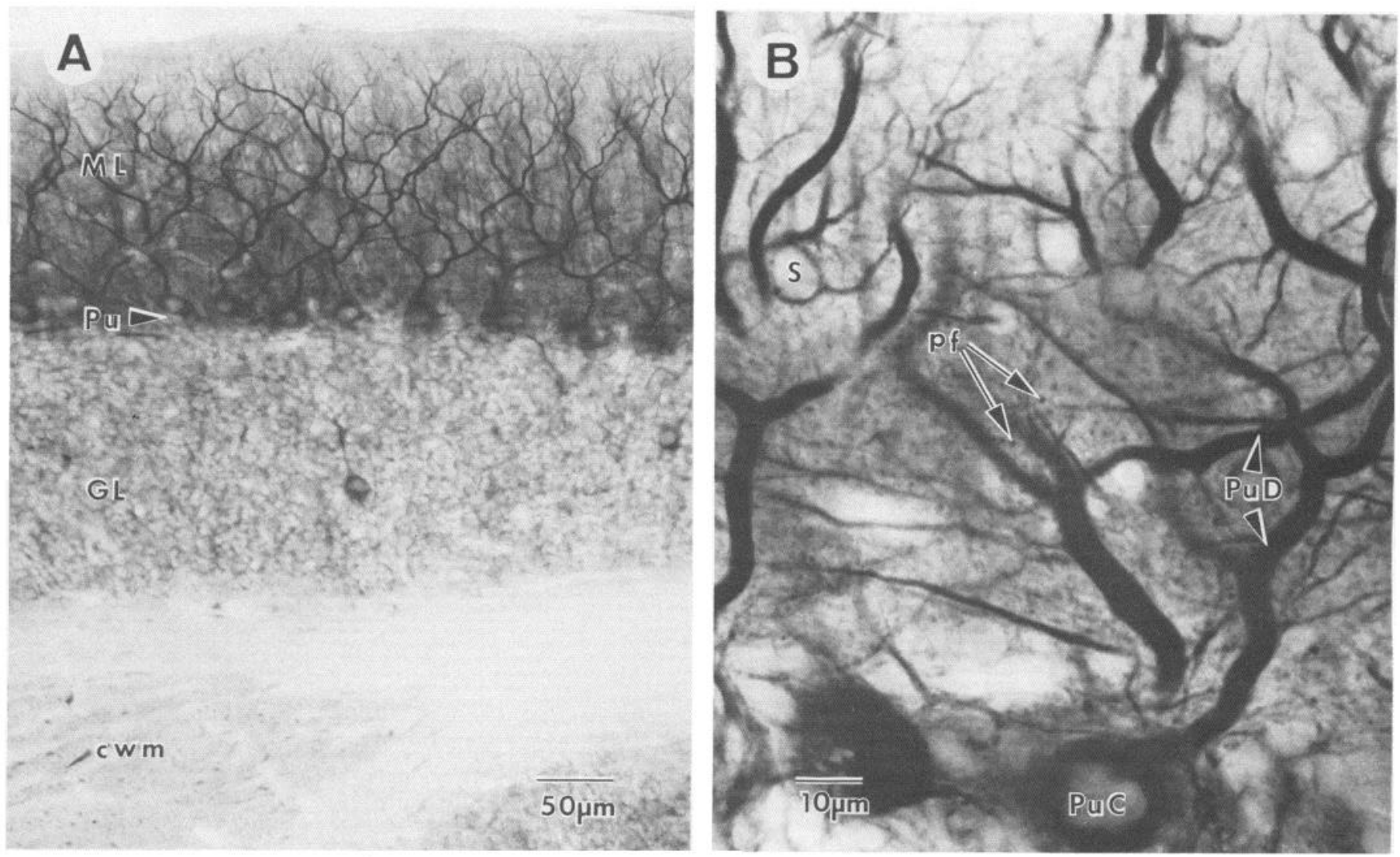

Figure 3. Cerebellar cortex of adult rat, stained by anti-MAP1. A, Low power micrograph showing strong staining in the cell bodies of the Purkinje cell layer $(P u)$ and in the dendrites expanding through the molecular layer $(M L)$. Staining intensity is reduced in the granular layer $(G L)$. Weak but distinct reaction occurs in axons in the cerebellar white matter $(\mathrm{cwm})$. B, MAP1 is distributed evenly through the Purkinje cell body $(P u C)$ and dendritic tree $(P u D)$. A stellate neuron $(S)$ is also stained, as are parallel fibers $(p f)$, scattered through the lower molecular layer. 

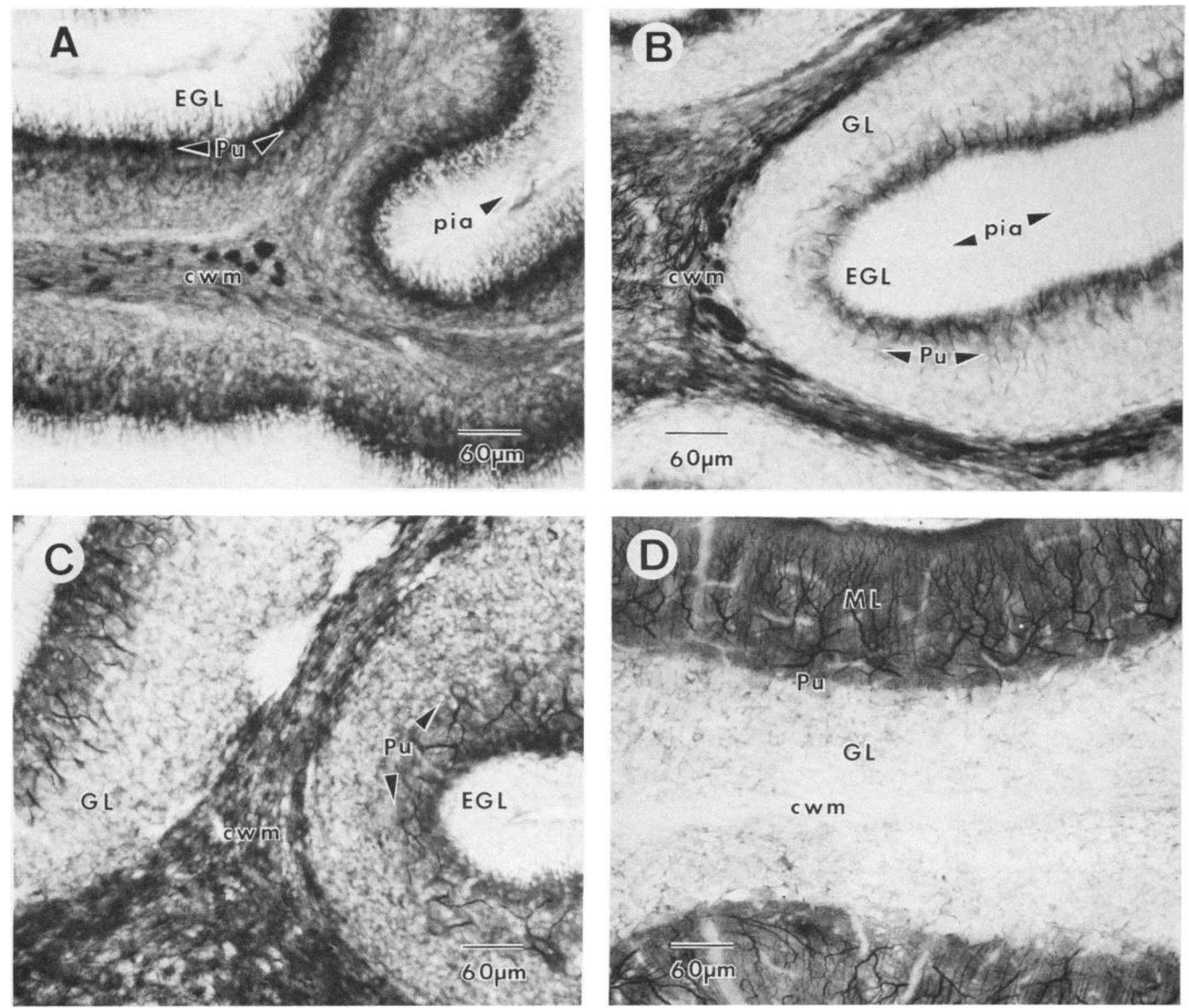

Figure 4. Developmental series showing the emergence of the mature MAP1 distribution pattern during cerebellar ontogenesis. A, At 3 days, axons of the central fiber tracts $(\mathrm{cWm})$ are strongly stained. Uniform labeling occurs in postmitotic neurons. Reaction density is higher in the thin band of forming molecular layer separating the Purkinje cell layer $(P u)$ from the external granular layer $(E G L)$. $B, A t 7$ days, MAP1 is distinctly localized. Intense staining occurs in axons of the central cerebellar tracts $(\mathrm{CWm})$. Purkinje cells $(P u)$ and the molecular layer overlying them are also strongly labeled, whereas reactivity is weaker in the internal granular layer (GL). C. At 10 days, strong reaction is detected in the cerebellar white matter (cwm), in Purkinje cells $(P u)$, and in the molecular layer which expands between Purkinje and external granular layers (EGL). Weaker levels of MAP1 are present in the internal granular layer (GL). $D$, In the adult cerebellum, the Purkinje cell layer $(P U)$ and the molecular layer $(M L)$ contain high concentrations of MAP1. White matter staining ( $C w m$ ) appears reduced. Lower level MAP1 staining persists in the granular layer (GL). Throughout development, no MAP1 is detected in the mitotic cells of the external granular layer ( $E G L)$. In $A$ and $B$ the pial surface is indicated (pia).

cells during the following stages of growth and in the adult cerebellum (Figs. $4 D$ and $5 C$ ).

Electron microscopy also demonstrates that, in the Purkinje cell body of 10-day-old rat, anti-MAP1 immune staining, distributed through the cytoplasm (Figs. 6 and $7 A$ ) and perisomatic spines (Fig. $7 B$, inset), is not associated with cytoskeletal elements. However, in the Purkinje cell axonal hillock and initial axon segment, it can be seen that microtubules are labeled by the antibody (Fig. $7 B$ ). In Purkinje cell dendrites the immunostaining is so intense that the reaction product has spread throughout the cytoplasm, only rarely allowing single microtubules to be resolved (Fig. 7, C and D). Nevertheless, it can be seen that MAP1 staining does not extend into the dendritic spines (Fig. 7C, inset).

\section{MAP3 appears transitorily in some types of axons, while persisting in others}

Adult situation. In the adult brain MAP3 occurs in both neurons and glia, but in neurons it is restricted to neurofilament-rich axons (Matus et al., 1983; Huber et al., 1985). Thus, axonal staining by anti-MAP3 is conspicuous in the white matter but virtually absent from parallel fiber axons (see Fig. 10C). Strong MAP3 reactivity is found in the cell bodies and processes of Bergmann glia in the molecular layer and in astrocytes in the granular layer (see Fig. 10D).

Developmental pattern. Staining of 3-day-old rat cerebellar sections (Fig. 8, $A$ and $B$ ) with monoclonal anti-MAP3 produces a reaction in all of the cerebellar cell types already formed, except for 

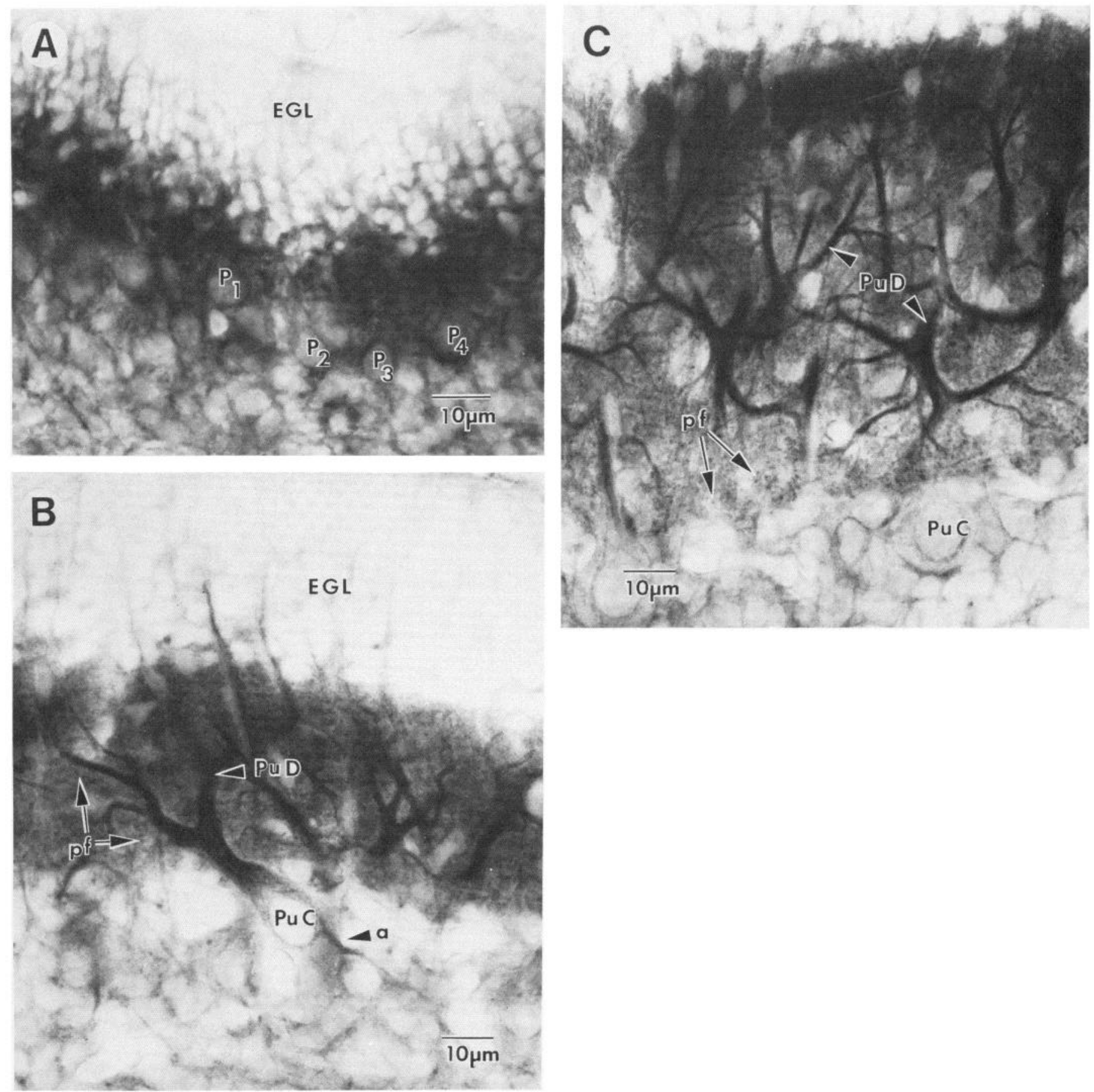

Figure 5. Anti-MAP1 staining on sections of developing cerebellum. A, At 3-days, anti-MAP1 weakly labels the densely packed neurons, producing uniform staining. The Purkinje cell layer is indicated by four marked cells $\left(P_{1}\right.$ to $\left.P_{4}\right)$, which show no evidence of MAP1 accumulation in any particular cellular compartment. Neither of the two antibodies reacts in the mitotic cells of the external granular layer $(E G L)$. $B$, At 7 days, intense staining fills the Purkinje cell body $(P u C)$, dendritic tree $(P u D)$, and the emerging axon (a). Strong reaction in parallel fibers of the molecular layer makes it difficult to resolve individual axonal profiles $(p f)$. Granule cell precursors in the external granular layer $(E G L)$ are unstained. $C$, MAP1 fills the expanded Purkinje cell dendrite ((PuD); reactivity in the cell body $((P u C)$ appears reduced. Strong reaction in recently formed parallel fibers produces uniform labeling of the superficial molecular layer, while in the lower region single axonal profiles $(p f)$ can be distinguished.

the germinative cells of the external granular layer. MAP3 is apparently expressed by differentiating neurons and glia but not by neuronal precursor cells. As cerebellar maturation proceeds, immunoreactivity becomes more distinctly localized and the level of background reactivity recedes. No MAP3 is detected in the Purkinje cell body at 10 days by light microscopy (Fig. 9, $A$ and $B$ ). The developing Purkinje cell dendritic tree appears as if negatively stained, outlined against a dark background of immunoreactive parallel fibers. In the internal granular layer MAP3 staining becomes restricted so that only astrocytes are stained from the third postnatal week on.

Whereas MAP3 reactivity in the cell bodies of 3-day cerebellum is 


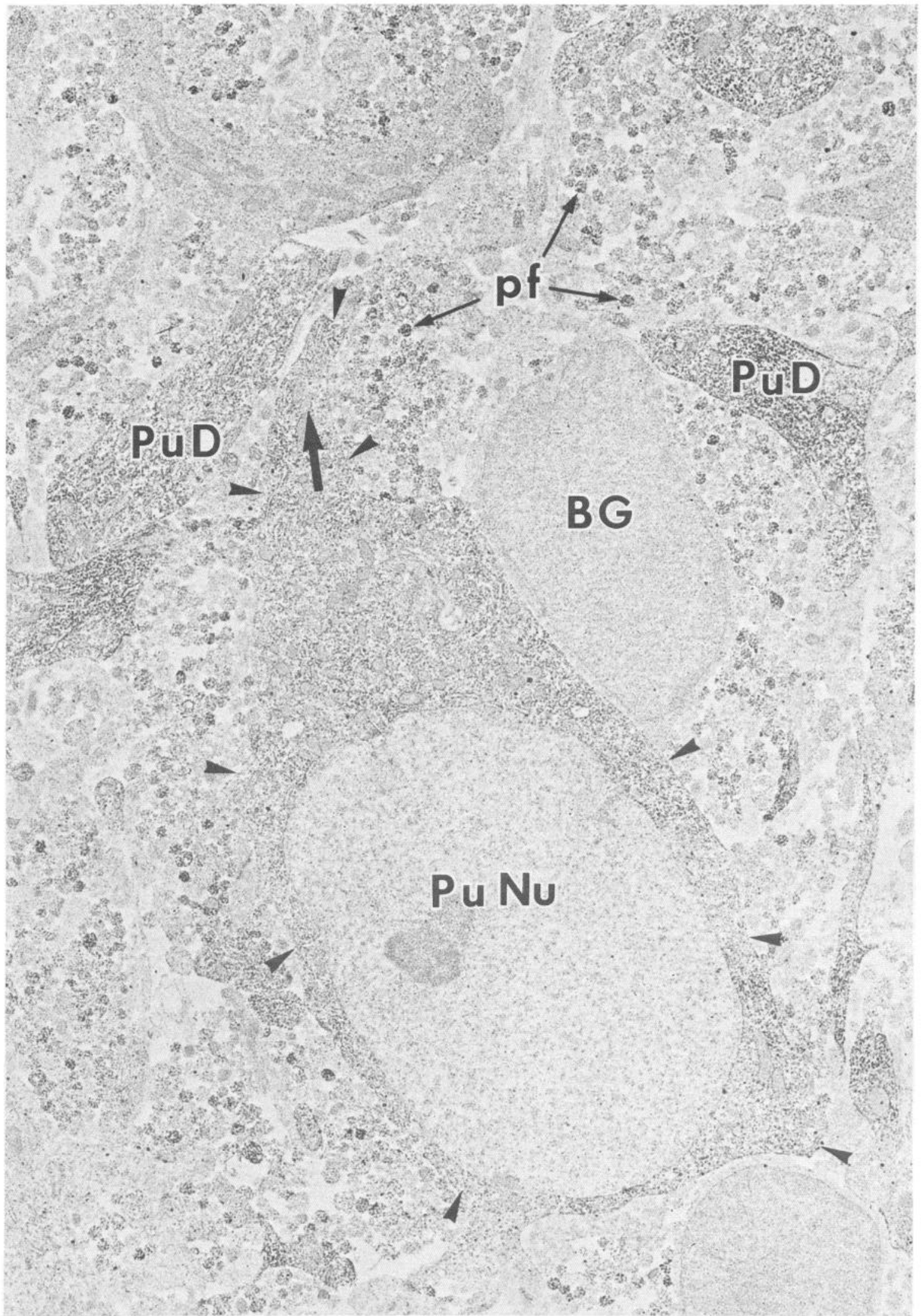

Figure 6. Electron micrograph of 10-day-old rat cerebellar cortex, stained by anti-MAP1. Immune reaction product fills the dendritic trunk (arrow) and the Purkinje cell cytoplasm (outlined by arrowheads) surrounding the unstained nucleus (PuNu). Large Purkinje cell dendrites (PuD) are also stained. Only a subset of the parallel fiber axonal profiles which make up the mass of the molecular layer is labeled by the antibody ( $p f$ ). No staining occurs in a Bergmann glia cell body $(B G)$. Magnification $\times 10,000$. 

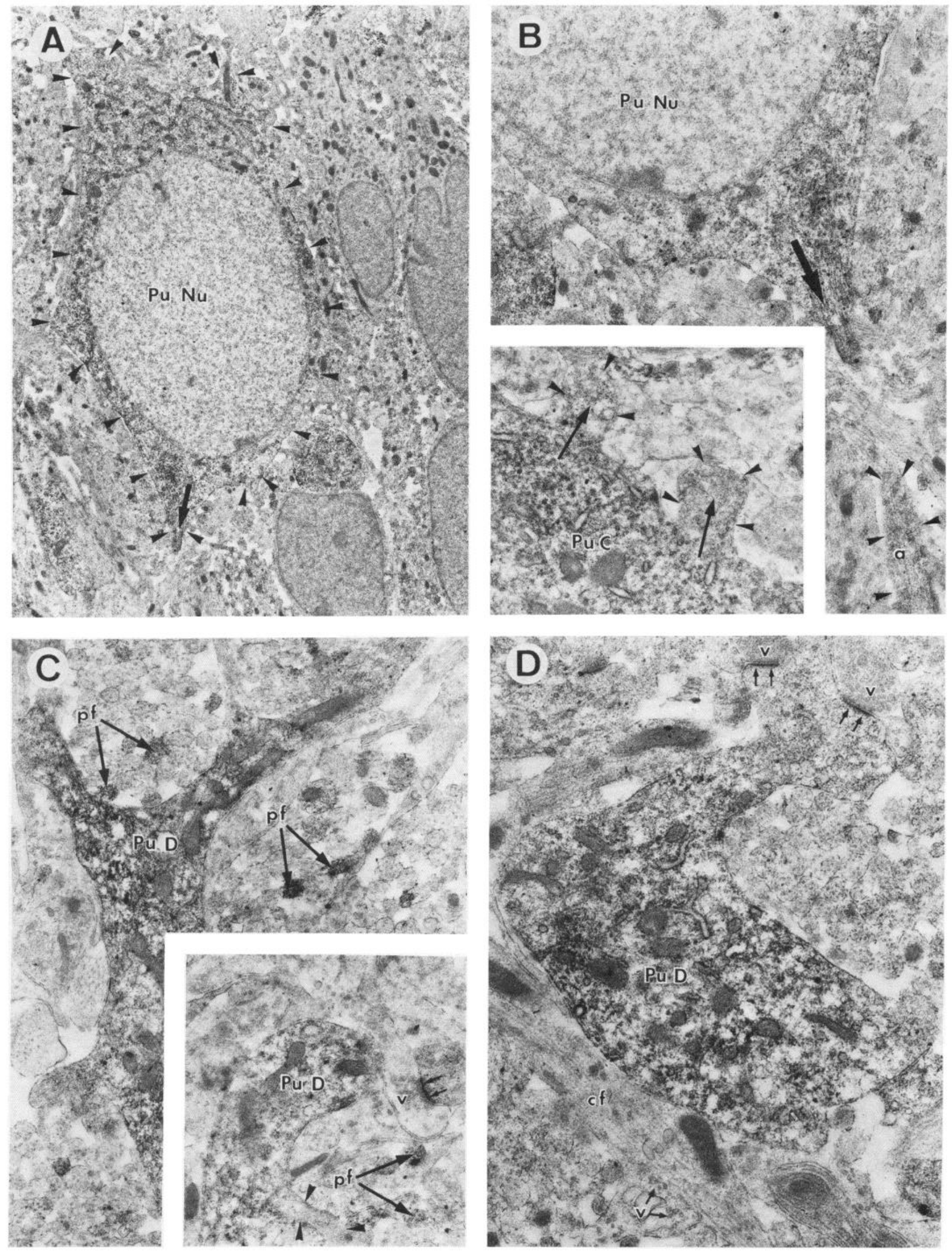

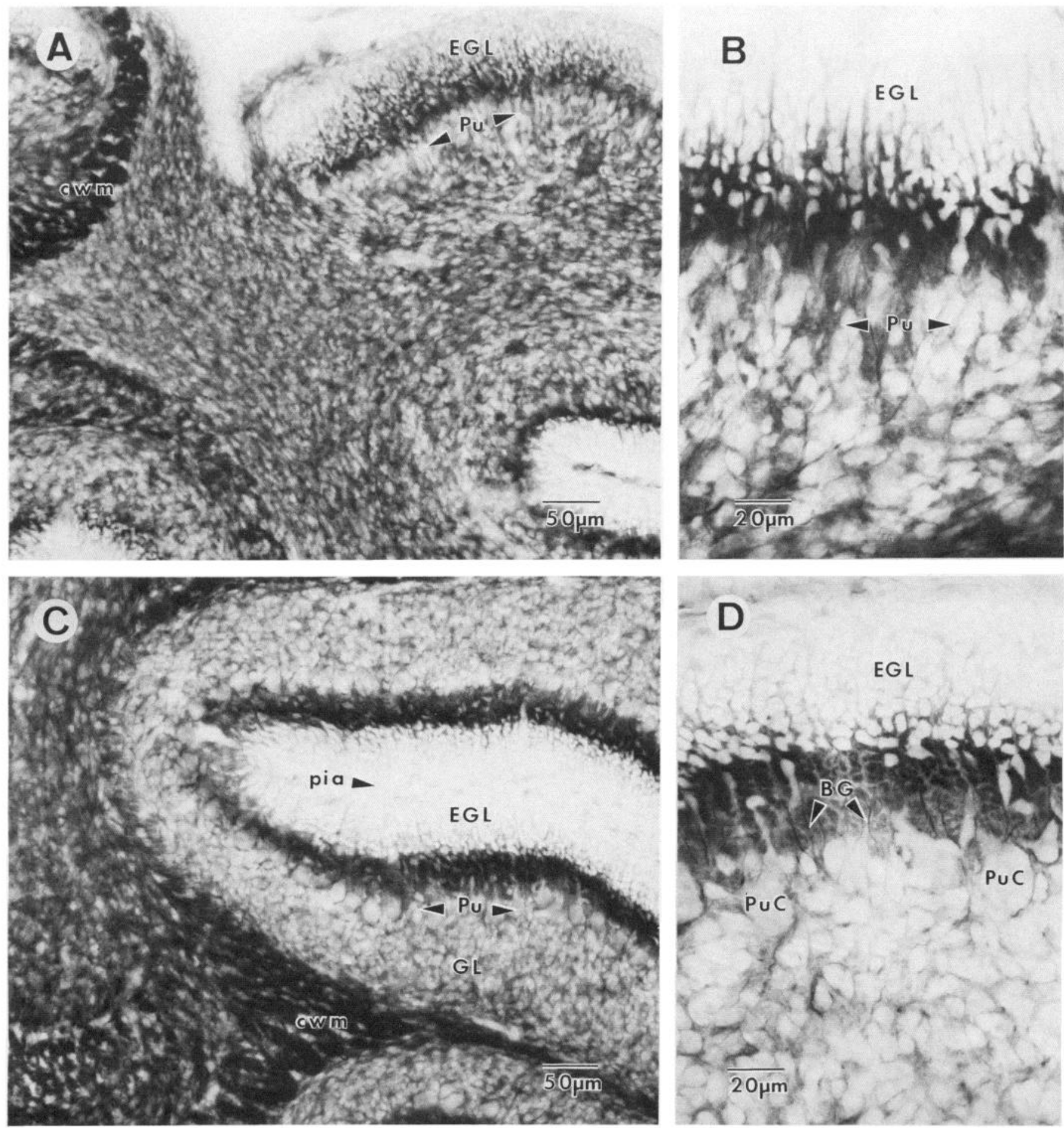

Figure 8. Vibratome sections of 3-and 7-day-old rat cerebellum, stained by anti-MAP3. A, At 3 days, reaction is concentrated in the central fiber tracts $(\mathrm{cWm})$ and in the developing molecular layer, which separates the unstained external granular layer $(E G L)$ from the Purkinje cells $(P u)$. B, Purkinje cell layer $(P u)$ and external granular layer (EGL) are not stained, but reaction is concentrated in the narrow band of molecular layer expanding between them. $C$, At 7 days distinct layering of the cerebellar cortex is established. High levels of reactivity are found in the central fiber tracts ( $\mathrm{cwm}$ ) and in the molecular layer, separating the unstained external granular $(E G L)$ and Purkinje cell $(P u)$ layers. Some reaction occurs in the internal granular layer $(G L)$. The pial surface is indicated (pia). $D$, Stained Bergmann glial fibers $(B G)$ extend through the strongly reactive molecular layer. Precursor cells in the external granular layer $(E G L)$ and Purkinje cell bodies $(P U C)$ are unstained.

Figure 7. Electron micrographs of 10-day-old rat cerebellar cortex, stained by anti-MAP1. A, Staining occurs in the Purkinje cell cytoplasm (outlined by arrowheads) and axonal hillock (arrow), whereas the nucleus $(P u N u)$ is not labeled. Magnification $\times 6,000$. $B$, At a higher magnification, individual labeled microtubules are resolved in the axonal hillock (arrow) and axon ( $a$, outlined by arrowheads) of the same cell. Pu $\mathrm{Nu}$, Purkinje cell nucleus. Magnification $\times$ 11,000. Inset, Staining reaction extends from the Purkinje cell cytoplasm (PuC) into somatic spines (arrows, outlined by arrowheads). Magnification $\times$ $14,000$. C, Immune reaction product fills a Purkinje cell dendrite $(P u D)$. Only a subset of the surrounding parallel fibers is immunolabeled ( $p f)$. Magnification $\times 16,000$. Inset, An unstained axon synapses onto a stained Purkinje cell dendrite $(P u D)$. Arrowheads indicate an unstained dendritic spine. Some parallel fibers are also stained $(p f), v$, axonal vesicles; small arrows, postsynaptic density. Magnification $\times 18,000 . D, A$ stained Purkinje cell dendrite $(P u D)$ receives two synaptic inputs. $v$, synaptic vesicles; small arrows, postsynaptic density. A passing axon, tentatively identified as a climbing fiber (cf) because of the dense array of microtubules and vesicles $(v)$, is unstained. Magnification $\times 18,000$. 

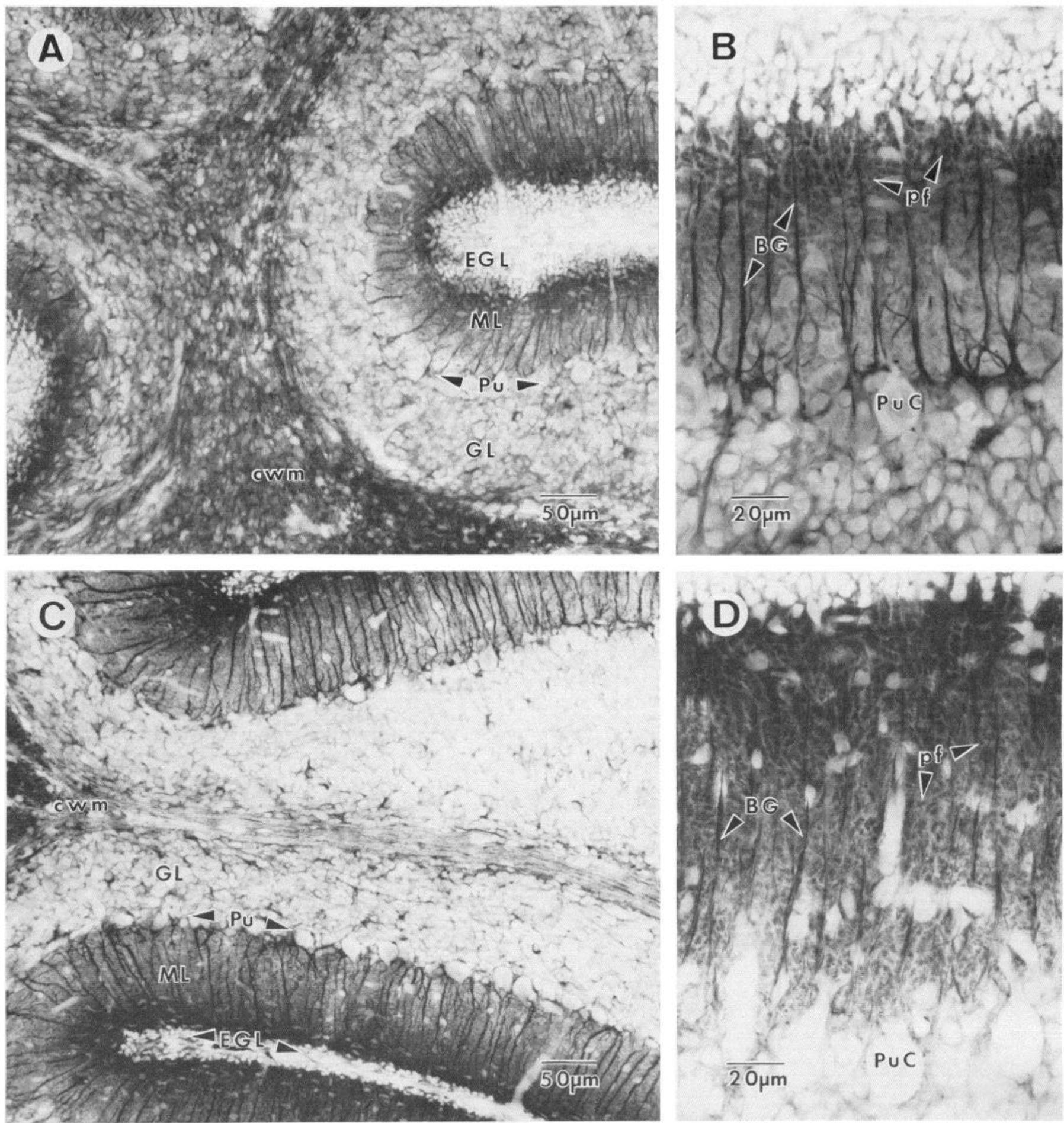

Figure 9. Cerebellar sections of 10- and 14-day-old rat, stained by anti-MAP3. A, At 10 days strong staining reaction is observed in the central fiber tracts $(\mathrm{Cwm})$ and in the molecular layer $(M L)$. Staining at a weaker level is also present in granule cells of the internal granular layer (GL). No reaction occurs in the external granular layer $(E G L)$ and in the Purkinje cell layer $(P u)$. B, Parallel fiber axons $(p f)$ and Bergmann glia $(B G)$ are intensely stained. Staining reaction is particularly dense in the more superficially positioned parallel fiber profiles. A Purkinje cell body $(P u C)$ is unstained. $C$, The staining pattern at 14 days is similar to the 10-day pattern, but reaction in the granular layer (GL) appears more distinctly localized in astrocytes and thin fibers. The external granular layer $(E G L)$ shrinks as it gets more and more depleted of granule cell precursors. $D$, Bergmann glia $(B G)$ and parallel fibers $(p f)$ of 14 -day-old rat cerebellum are intensely stained. No reaction occurs in Purkinje cell bodies $(P u C)$.

rather weak and diffuse, intense antibody staining is present in the central fiber bundles and also in the developing molecular layer (Fig. $8, A$ and $B$ ). At 7 days postnatal (Fig. $8, C$ and $D$ ), immune reactivity in the molecular layer is distinctly associated with parallel fibers and with Bergmann glia. Anti-MAP3 reveals the typical tortuous path that these glial fibers pursue through the expanding molecular and the external granular layer during early development (Fig. 8D). Bergmann fibers start to show their adult morphology after 10 days, radiating straight out from the Purkinje cell layer toward the cerebellar surface (Fig. 9, $B$ and D). High intensity staining of white matter axons and Bergmann glia fibers persists in the adult cerebellum (Fig. 10, $C$ and D). 

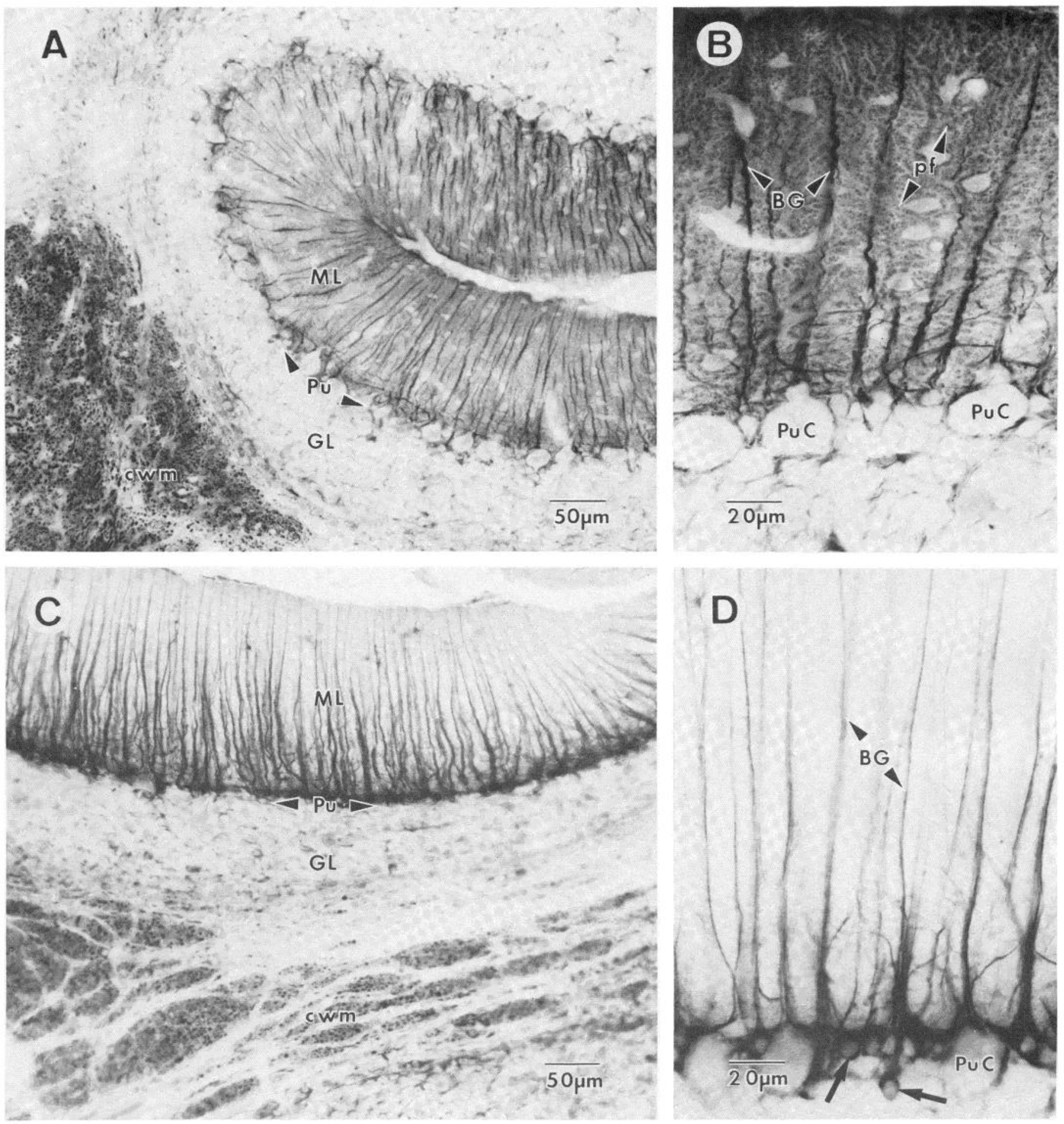

Figure 10. Sections of 20-day-old rat cerebellum, stained by anti-MAP3. A, At 20 days, the cerebellar white matter (cwm) and the molecular layer (ML) are strongly stained. Staining in the granular layer $(G L)$ is confined to astrocytes. The external granular layer has disappeared. No reaction is present in Purkinje cells $(P u)$. B, Bergmann glia $(B G)$ and parallel fibers $(p f)$ are strongly stained in the molecular layer of 20-day-old rat. Purkinje cell bodies $(P u C)$ are unstained. $C$, In the adult cerebellum staining is conspicuous in white matter axons $(\mathrm{cwm})$ and in the radiating glial fibers of the molecular layer $(M L)$. Astrocytes in the granular layer $(G L)$ are also stained, but no reaction occurs in Purkinje cells $(P u)$. $D$, The Bergmann glial fibers $(B G)$ are the dominant stained element of adult molecular layer. Staining has disappeared from parallel fiber axons. Purkinje cell bodies $(P u C)$ are not reactive, whereas the cell bodies of Bergmann glia (arrows) are intensely stained.

The most striking change of MAP3 distribution is found in the developing granule cells. Their precursors in the external granular layer do not express the protein. It first appears after the cells have completed their final mitosis, when there is weak staining of the cell bodies in the internal granular layer, coupled with intense staining of their axons. MAP3 reactivity is particularly high in the most recently formed parallel fibers, resulting in intense antibody staining in the more superficial axons (Fig. 9, $A$ to $D$ ). Anti-MAP3 labeling of parallel fibers decreases with advancing cerebellar development. Concomitantly, the lower level reaction in granule cells of the internal granular 

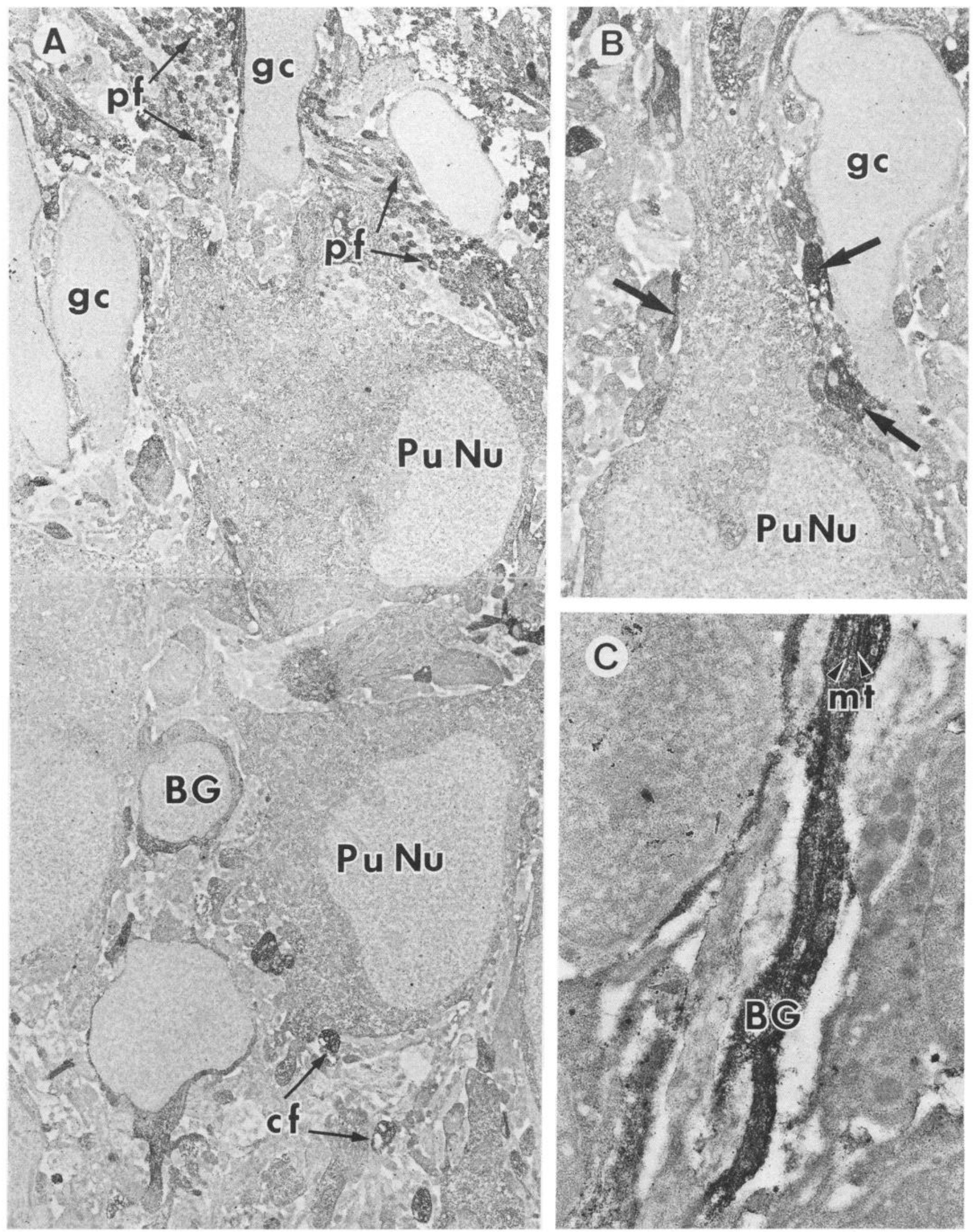

Figure 11. Electron micrographs of 10-day-old rat cerebellar cortex, stained by anti-MAP3. $A$, Strong immune reaction occurs in parallel fiber profiles ( $\rho f$ ). The cell body of a Bergmann glia $(B G)$ is also stained. No reaction has occurred in migrating granule cells ( $g c)$ and in Purkinje cells ( $P u$ Nu, Purkinje cell nucleus). Large stained fiber profiles surrounding the Purkinje cells are tentatively identified as climbing fiber axons (cf). Magnification $\times 5,000$. $B$, The unstained dendritic trunk of a Purkinje cell ( $P u$ Nu, Purkinje cell nucleus) is surrounded by heavily labeled fibers (arrows), probably climbing fiber axons. A migrating granule cell $(g c)$ is unstained. Magnification $\times 7,500$. C. Bergmann glia $(B G)$ extending through the lower region of the external granular layer is intensely stained. Individual immunolabeled microtubules $(m t)$ can be distinguished. Magnification $\times 17,500$. 

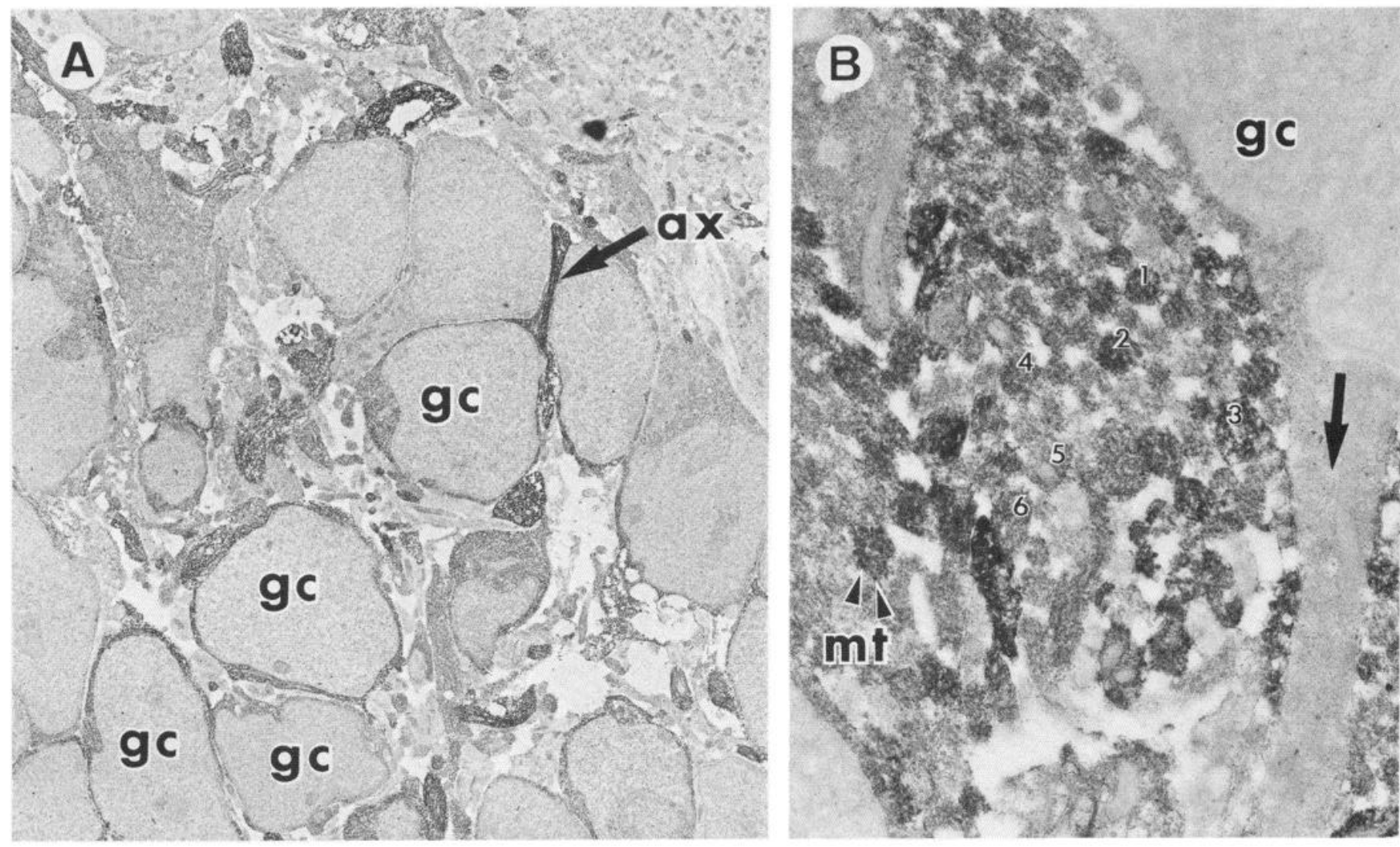

Figure 12. Electron micrographs of 10-day-old rat cerebellum, stained by anti-MAP3. A, Granule cells $(g c)$ that have arrived in the internal granular layer are immunoreactive. The stained process emerging from a granule cell and extending straight toward the molecular layer is tentatively identified as a granule cell axon (ax). Magnification $\times 3,000$. B, A migrating granule cell $(g c)$ with the characteristic leading process (arrow) is not stained. Surrounding paralle fibers are all reactive, but staining intensity varies. Some axonal profiles ( 1 to 3 ) are heavily labeled, whereas others (4 to 6$)$ are less intensely stained. Magnification $\times 14,000$

layer gradually disappears (Figs. $9, A$ and $C$, and $10 A$ ). In the adult cerebellum there is no cytoplasmic staining of granule cell bodies, and the antigen, which at 20 days (Fig. 10, $A$ and $B$ ) is still present in parallel fibers, has disappeared from these axons, with the exception of a few scattered profiles encountered in the lower third of the molecular layer in some animals.

Immunoelectron microscopic examination of 10-day-old rat cerebellum confirms the localization of MAP3 as seen in the light microscope. Reaction product is found in the cell bodies and processes of Bergmann glia (Fig. 11, $A$ and $C$ ). Axons running in the central fiber tracts, mostly not yet myelinated, are also stained by anti-MAP3 (not shown), as are fiber profiles surrounding the Purkinje cell soma and dendritic trunk, which we have tentatively identified as climbing fiber axons (Fig. 11, $A$ and $B$ ). Staining in all of these processes is associated with microtubules, whereas reaction in the cell bodies is cytoplasmic. At 10 days postnatal, MAP3 antigen is present in microtubules of most parallel fiber profiles, but staining intensity varies (Fig. 12B). A subset of granule cells, which have completed their migration and are now situated in the internal granular layer, also expresses the protein (Fig. 12A). However, MAP3 is not detected in the soma and the leading process of migrating granule cells (Figs. $11 B$ and $12 B$ ).

\section{Discussion}

Our results indicate that, during cerebellar development, changes can occur both in the type of cell in which a particular MAP protein is expressed and in its cytoplasmic distribution within the same cell. MAP1 presents an example of a cytoplasmic distributional change, its high concentration in axons of neonatal brain falling to levels which are markedly lower than those present in the dendrites of adult tissue. MAP3 provides an example of a change in cell type expression, appearing only transitorily in granule cells during development. Within these cells MAP3 is concentrated in the newly formed parallel fibers which grow out as the cells migrate from the cerebellar surface toward the internal granular layer. Thus, although it is present only transiently, MAP3 maintains the same specific association with axons, which in other neuronal types is characteristic both during development and in the adult brain.

In Bergmann glia both MAP3 antigen and the glial fibrillary acidic protein antigen (Bignami and Dahl, 1973, 1974) are detected at a very young developmental stage ( $\sim 3$ days postnatal), suggesting that glial filaments and microtubules are formed synchronously. However, in neurons, the appearance of MAP3 precedes the appearance of neurofilament proteins. In the cerebellar white matter low levels of neurofilament protein activity are first detected in the second postnatal week, and the adult distribution pattern is only established 3 weeks postnatally (our unpublished observations).

The distribution of MAP3-containing microtubules in the adult brain coincides with the distribution pattern of intermediate filaments. Therefore, MAP3 is a candidate for a cross-linker between microtubules and neurofilaments (Huber et al., 1985). Although MAP3 might cross-link adult microtubules and neurofilaments, its role during axonal outgrowth seems to be different. This notion is supported by the observation that parallel fibers, which do not contain neurofilaments, display MAP3 during their period of formation, but not after terminal maturation. It is the appearance of neurofilaments which characterizes this maturation in other axons (Peters and Vaughn, 1967; Lasek, 1981). Information as to the function of MAP3 in differentiating axons is provided by a series of experiments on the role of MAP3 in microtubule polymerization. These data suggest that 
in vitro assembly of tubulin subunits into microtubules is reduced if the system is depleted of MAP3 (G. Huber and A. Matus, manuscript in preparation).

MAP2 and the formation of dendrites. MAP'2 is associated with dendrites from the earliest stages of dendritic outgrowth on. In the adult brain MAP2 displays a most restricted distribution pattern, being associated only with dendritic microtubules (Bernhardt and Matus, 1984; Caceres et al., 1984). This contrasts with MAPs 1 and 3 , both of which are not specific to a single type of cellular process (MAP1 is present in axons and dendrites; MAP3 is present in axons and glial processes). The distribution of MAP2 suggests that its role is specific to dendrites, whereas the other MAPs might subserve more generalized functions, common to various kinds of cell processes. One such function of MAP2 might be in dendritic plasticity. The results of this developmental study show that high levels of MAP2 are found in dendrites during the period of highest plasticity (Altman and Anderson, 1972; Sotelo, 1978; see also Jacobson, 1978). MAP2 is detected in Purkinje cell dendrites before organized microtubules are present (Altman, 1972; Bernhardt and Matus, 1982). A regulatory role of MAP2 in the transition from free tubulin subunits to microtubules could account for the change from a more plastic to a more stable state of dendritic architecture.

Interaction of MAP1 with MAP2 and MAP3. During neuronal development MAP1 is always codistributed with either MAP2 or MAP3. The effect of MAP1 on microtubule assembly is not yet elucidated. Although many studies indicate that a heat-stable MAP fraction (devoid of MAP1) is sufficient to restore assembly capacity to purified tubulin (Weingarten et al., 1975; Fellous et al., 1976; Herzog and Weber, 1978; Kim et al., 1979), experiments using purified MAP1 have produced conflicting results. One such study reports a direct effect of MAP1 on in vitro assembly (Kuznetsov et al., 1981), whereas another one found no influence of MAP1 on in vitro microtubule polymerization (Villasante et al., 1980).

A possible explanation for the differing findings reported from in vitro assembly systems is suggested by the immunohistochemical data. MAP1 might be involved in regulating the promoting capacities of MAP2 and MAP3. In vitro studies indicate that MAP2 alone is not sufficient to promote assembly of microtubules in young brain (Mareck et al., 1980; Francon et al., 1982). In Purkinje cell dendrites, which contain high amounts of MAP2 from the earliest postnatal stages on (Bernhardt and Matus, 1982; Matus et al., 1983; Burgoyne and Cumming, 1984), microtubules are only detected by electron microscopy in the second postnatal week (Altman, 1972; Bernhardt and Matus, 1982). However, growing axons are rich in microtubules right from the onset of formation. During cerebellar development, MAPT is detected first in axons and only later in dendrites. Hence the presence of MAP1 correlates with microtubule formation in both kinds of processes. These observations suggest the hypothesis that MAP1 interacts with other MAPs in promoting microtubule assembly.

\section{References}

Altman, J. (1972) Postnatal development of the cerebellar cortex in the rat. II. Phases of maturation of Purkinje cells and the molecular layer. J. Comp. Neurol. 145: 399-464.

Altman, J. and W. J. Anderson (1972) Experimental reorganization of the cerebellar cortex. I. Morphological effects of elimination of all microneurons with prolonged X-irradiation started at birth. J. Comp. Neurol. 146: 355406.

Bernhardt, R., and A. I. Matus (1982) Initial phase of dendrite outgrowth: Evidence for the involvement of high molecular weight microtubule-associated proteins (HMWP) before the appearance of tubulin. J. Cell Biol. 92: 589-593

Bernhardt, R., and A. I. Matus (1984) Light and electron microscopic studies of the distribution of microtubule-associated protein 2 in rat brain: $A$ difference between dendritic and axonal cytoskeletons. J. Comp. Neurol. 226: 203-219.

Bignami, A, and D. Dahl (1973) Differentiation of astrocytes in the cerebellar cortex and the pyramidal tracts of the newborn rat. An immunofluorescence study with antibodies to a protein specific to astrocytes. Brain Res.
49: 393-402

Bignami, A., and D. Dahl (1974) Astrocyte-specific protein and radial glia in the cerebral cortex of newborn rat. Nature 252: 55-56.

Bloom, G. S., T. A. Schoenfeld, and R. B. Vallee (1984) Widespread distribution of the major polypeptide component of MAP1 (microtubuleassociated protein 1) in the nervous system. J. Cell Biol. 98: 320-330.

Borisy, G. G., J. M. Marcum, J. B. Olmsted, D. B. Murphy, and K. A. Johnson (1975) Purification of tubulin and of associated high molecular weight proteins from porcine brain and characterization of microtubule assembly in vitro. Ann N. Y. Acad. Sci. 253: 107-132.

Burgoyne, R. D., and R. Cumming (1984) Ontogeny of microtubule-associated protein 2 in rat cerebellum: Differential expression of the doublet polypeptides. Neuroscience 11: 157-167.

Caceres, A., M. R. Payne, L. I. Binder, and O. Steward (1983) Immunohistochemical localization of actin and microtubule-associated protein MAP2 in dendritic spines. Proc. Natl. Acad. Sci. U. S. A. 80: 1738-1742.

Caceres, A., L. I. Binder, M. R. Payne, P. Bender, L. Rebhun, and O. Steward (1984). Differential subcellular localization of tubulin and the microtubuleassociated protein MAP2 in brain tissue as revealed by immunohistochemistry with monoclonal hybridoma antibodies. J. Neurosci. 4: 394-410.

Cleveland, D. W., S. Hwo, and M. W. Kirschner (1977) Purification of tau, a microtubule-associated protein that induces assembly of microtubules from purified tubulin. J. Mol. Biol. 116: 207-225.

Daniels, M. P. (1972) Colchicine inhibition of nerve fiber formation in vitro. J. Cell Biol 53: 164-176.

De Camilli, P., P. E. Miller, F. Navone, W. E. Theurkauf, and R. B. Vallee (1984) Distribution of microtubule-associated protein 2 in the nervous system of the rat studied by immunofluorescence. Neuroscience $11: 819$ 846 .

Fellous, A., J. Francon, M. A. Lennon, and J. Nunez (1976) Initiation of neurotubulin polymerization and rat brain development. FEBS Lett. 64 : 400-403.

Francon, J., A. M. Lennon, A. Fellous, A. Mareck, M. Pierre, and J. Nunez (1982) Heterogeneity of microtubule-associated proteins and brain development. Eur. J. Biochem. 129: 465-471.

Herzog, W., and K. Weber (1978) Fractionation of brain microtubule-associated proteins. Eur. J. Biochem. 92: 1-8.

Huber, G., and A. Matus (1984a) Differences in the cellular distribution of two microtubule-associated proteins, MAP1 and MAP2, in rat brain. J. Neurosci. 4: 151-160.

Huber, G., and A. Matus (1984b) Immunocytochemical localization of microtubule-associated protein 1 in rat cerebellum using monoclonal antibodies. J. Cell Biol. 98: 777-781.

Huber, G., D. Alaimo-Beuret, and A. Matus (1985) MAP3: Characterization of a novel microtubule-associated protein. J. Cell Biol. 100: 496-507.

Jacobson, M. (1978) Developmental Neurobiology, Plenum Press, New York. Kim, H., L. I. Binder, and J. L. Rosenbaum (1979) The periodic association of MAP2 with brain microtubules in vitro. J. Cell Biol. 80: 266-276.

Kuznetsov, S. A., V. I. Rodionov, V. I. Gelfand, and V. A. Rosenblat (1981) Microtubule-associated protein MAP1 promotes microtubule assembly in vitro. FEBS Lett. 135: 241-244.

Lasek, R. J. (1981) The dynamic ordering of the cytoskeleton. Neurosci. Res. Program. Bull. 19: 7-32.

Mareck, A., A. Fellous, J. Francon, and J. Nunez (1980) Changes in composition and activity of microtubule-associated proteins during brain development. Nature 284: 353-355.

Matus, A. I., R. Bernhardt, and T. Hugh-Jones (1981) High molecular weight microtubule-associated proteins are preferentially associated with dendritic microtubules in brain. Proc. Natl. Acad. Sci. U. S. A. 78: 3010-3014.

Matus, A., G. Huber, and R. Bernhardt (1983) Neuronal microdifferentiation. Cold Spring Harbor Symp. Quant. Biol. 48: 775-782.

Palay, S. A., and V. Chan-Palay (1974) Cerebellar Cortex. Cytology and Organization, Springer-Verlag, Berlin.

Peters, A., and J. Vaughn (1967) Microtubules and filaments in the axons and astrocytes of early postnatal rat optic nerves. J. Cell Biol. 32: 113119.

Seeds, N. W., A. G. Gilman, T. Amano, and M. W. Nirenberg (1970) Regulation of axon formation by clonal cell lines of a neuronal tumor. Proc. Natl. Acad. Sci. U. S. A. 60: 160-167.

Sloboda, R. D., W. L. Dentler, and J. L. Rosenbaum (1976) Microtubuleassociated proteins and stimulation of tubulin assembly in vitro. Biochemistry 15: 4497-4505.

Sotelo, C. (1978) Purkinje cell ontogeny: Formation and maintenance of spines. Prog. Brain Res. 48: 149-170.

Villasante, A., J. de la Torre, R. Manso-Martinez, and J. Avila (1980) Micro- 
tubule-associated protein MAP1 is not implicated in the polymerization of microtubules. Eur. J. Biochem. 112: 611-616.

Weingarten, M. D., A. H. Lockwood, S. Y. Ho, and M. Kirschner (1975) A protein factor cssential for microtubule assembly. Proc. Natl. Acad. Sci. U. S. A. $72: 1858-1862$.

Wiche, G. E. Briones, H. Hirt, R. Kepler, U. Artlieb, and H. Denk (1983) Differential distribution of microtubule-associated proteins MAP-1 and MAP. 2 in neurons of rat brain and association of MAP-1 with microtubules of neuroblastoma cells (clone $\mathrm{N}_{2} \mathrm{~A}$ ). EMBO J. 2: 1915-1920.

Witman, G. B., D. W. Cleveland, M. D. Weingarten, and M. W. Kirschner (1976) Tubulin requires tau for growth on microtubule initiating sites. Proc. Natl. Acad. Sci. U. S. A. 73: 1970-4971.

Yamada, K. M., B. S. Spooner, and N. K. Wessells (1970) Axon growth: Roles of microfilaments and microtubules. Proc. Natl. Acad. Sci. U. S. A. 66: $1206-1212$. 